\title{
Examination of the Role of cGMP in Long-term Potentiation in the CA1 Region of the Hippocampus
}

\author{
David K. Selig, ${ }^{1}$ Michele R. Segal, ${ }^{4}$ Dezhi Liao, ${ }^{5}$ Robert C. Malenka, ${ }^{1,2}$ \\ Roberto Malinow, ${ }^{5}$ Roger A. Nicoll, ${ }^{2,3}$ and John E. Lisman ${ }^{4,6}$ \\ Departments of ${ }^{1}$ Psychiatry, ${ }^{2}$ Physiology, and ${ }^{3}$ Molecular and Cellular Pharmacology \\ University of California, San Francisco, California 94143 \\ ${ }^{4}$ Biology Department and Volen Center for Complex Studies \\ Brandeis University, Waltham, Massachusetts 02254 \\ ${ }^{5}$ Cold Spring Harbor Laboratory \\ Cold Spring Harbor, New York 11724
}

\begin{abstract}
The mechanisms underlying the generation of NMDA receptor-dependent LTP in the CA1 region of the hippocampus continue to receive a great deal of attention because of the postulated importance of LTP as a synaptic mechanism for learning and memory. It is well accepted that the initial induction of LTP occurs in the postsynaptic cell, but the site of expression remains controversial. One prominent hypothesis is that LTP involves the release of one or more retrograde messengers that act on the presynaptic terminal to enhance transmitter release. Recently, evidence has been presented that retrograde messengers function to activate presynaptic guanylyl cyclase and that the resulting rise in presynaptic cGMP levels, when accompanied by presynaptic activity, is responsible for generating an early component of LTP. We have tested this hypothesis by examining whether synaptic strength is increased by coupling tetanic stimulation with application of a membrane-permeable analog of cGMP. The experiments were done in the presence of an NMDA receptor antagonist to block postsynaptic induction mechanisms. Under a variety of
\end{abstract}

${ }^{6}$ Corresponding author. experimental conditions, this manipulation failed to generate LTP, suggesting that an increase in cGMP levels accompanied by presynaptic activity is not sufficient to generate LTP in the CA1 region of the hippocampus.

\section{Introduction}

Long-term potentiation (LTP) in hippocampal CA1 synapses has served as a model for the cellular changes that underlie learning and memory in mammals, and there is, thus, great interest in elucidating its molecular mechanisms. It is now well accepted that the induction of LTP depends on processes in the postsynaptic cell, specifically activation of $N$-methyl-D-aspartate (NMDA) receptors and the consequent rise in postsynaptic calcium concentration (for review, see Bliss and Collingridge 1993; Nicoll and Malenka 1995). However, the site of expression has been difficult to determine definitively, and, as yet, no consensus has been reached (Kullmann and Siegelbaum 1995). Nevertheless, it is clear that if the expression of LTP involves enhanced release of neurotransmitter, a retrograde messenger, produced in the postsynaptic cell and affecting presynaptic function, is mandatory. Several molecules have been suggested to play such a role, including arachidonic acid, carbon monoxide (CO), and nitric oxide (NO) (Bliss and Collingridge 1993; Williams et al. 1993a; for review, see Bear and Malenka 1994). Because all of these molecules can activate guanylyl cyclase, a particularly attractive

LEARNING \& MEMORY 3:42-48 (c) 1996 by Cold Spring Harbor Laboratory Press ISSN1072-0502/96 \$5.00

$$
\begin{array}{llllllllllllllll}
L & E & A & R & N & I & N & G & \boldsymbol{\bigotimes} \\
42 & M & E & M & O & R & Y
\end{array}
$$


hypothesis is that activation of this enzyme and the resultant increase in presynaptic cGMP levels coupled with presynaptic activity cause a long-lasting enhancement in transmitter release. Directly supporting this hypothesis is the demonstration that a tetanic stimulus given in the presence of an NMDA receptor antagonist elicits LTP if a membrane-permeable analog of cGMP is present (Zhuo et al. 1994). Furthermore, it was found that in culture, loading presynaptic hippocampal cells with cGMP also caused LTP when paired with a tetanus, again given in the presence of an NMDA receptor antagonist (Arancio et al. 1995). Additional evidence for the involvement of cGMP was the finding that LTP can be blocked by inhibitors of guanylyl cyclase or cGMP-dependent protein kinase (Zhuo et al. 1994; Arancio et al. 1995). The conclusion from these experiments was that LTP involves the generation of a retrograde messenger that activates presynaptic guanylyl cyclase. The resulting increase in presynaptic cGMP levels then causes a sustained enhancement of transmitter release from terminals that were activated while cGMP levels were elevated.

Other investigators have had difficulty in observing the same effects of cGMP analogs on synaptic strength (Irving et al. 1993; Schuman et al. 1994). One possible explanation for this apparent discrepancy is that, like the ability of NO synthase inhibitors to block LTP (Haley et al. 1993; Williams et al. 1993b), the ability of cGMP to cause LTP depends critically on the experimental conditions. Because of the potential significance of these observations in elucidating the site and mechanisms of LTP expression, we have reexamined the effects on synaptic strength of pairing tetanic stimulation (in the presence of an NMDA receptor antagonist) with application of 8-bromocGMP using a variety of experimental conditions in several different laboratories. This experiment was deemed critical because it bypasses postsynaptic NMDA receptors during the induction of LTP and strongly implicates processes within the presynaptic cell as being important for the generation of LTP.

\section{Materials and Methods}

Standard procedures were used to prepare hippocampal slices from either young rats (14-26 days old) (New York and Boston groups) or adult female guinea pigs (San Francisco group). After at least a 1-hr recovery period, slices were transferred to the recording chamber where they were submerged beneath a continuously superfusing solution saturated with $95 \% \mathrm{O}_{2}$ and $5 \% \mathrm{CO}_{2}$. A cut was made between the $\mathrm{CA} 3$ and $\mathrm{CA} 1$ regions to prevent propagation of epileptiform activity. The composition of solutions and the conditions varied slightly between laboratories. The Boston group used a solution containing (in $\mathrm{mM}$ ): $\mathrm{NaCl}, 120$; $\mathrm{KCl}, 2.5 ; \mathrm{MgSO}_{4}, 1.3 ; \mathrm{CaCl}_{2}, 2.5 ; \mathrm{NaH}_{2} \mathrm{PO}_{4}, 1$; $\mathrm{NaHCO}_{3}, 26$; and dextrose, 10. The temperature was $30^{\circ} \mathrm{C}$. Stimulation strength was set to produce $50 \%$ maximal response. The New York group used two solutions: one the same as that of Zhuo et al. (1994) (four experiments) and the other the standard one used in the New York group laboratory (five experiments) (in $\mathrm{mm}$ ): $\mathrm{NaCl}, 119 ; \mathrm{KCl}, 2.5$; $\mathrm{MgCl}_{2}, 1.3 ; \mathrm{CaCl}_{2}, 2.5 ; \mathrm{NaHCO}_{3}, 26.2 ; \mathrm{NaH}_{2} \mathrm{PO}_{4}, 1$; and $\mathrm{D}$-glucose, 11. Results with the two solutions were similar and thus were pooled. Picrotoxin $(100 \mu \mathrm{M})$ was used in all experiments. The temperature was $25^{\circ} \mathrm{C}$. Stimulation strength was set to produce $50 \%$ of the maximal response. The San Francisco group used a solution identical to that used by Zhuo et al. (1994). Picrotoxin (100 $\mu \mathrm{M})$ was used in all experiments. The temperature was $30^{\circ} \mathrm{C}$. The stimulation strength was set so that the amplitude of the field EPSP was $0.5-0.7 \mathrm{mV}$. Standard extracellular recording techniques were used to record field EPSPs in the stratum radiatum. The New York group stimulated a single pathway at the rate of $0.033 \mathrm{~Hz}$. The Boston group alternately stimulated two independent inputs, each at the rate of $0.033 \mathrm{~Hz}$. The San Francisco group alternately stimulated two independent inputs, each at the rate of $0.02 \mathrm{~Hz}$. Data were acquired and analyzed on-line using custom software. Summary graphs were generated as described previously (Malinow et al. 1988; Huang et al. 1992). All summary data is reported as mean \pm s.E.M. Drugs used were 8-bromo-cGMP (RBI, CalBiochem), DL-APV (Sigma, RBI), Picrotoxin (Sigma), and D-APV (Tocris Neuramin ).

This collaboration grew out of our common interest in the role of second messengers in LTP. It was agreed to test in parallel a previously reported crucial experiment in which potentiation could be induced by cGMP analogs, despite block of the NMDA channel (Zhuo et al. 1994). It was agreed that each group would use its own methodology. We further agreed that the results would not be shared until data analysis was complete and final summary graphs were constructed.

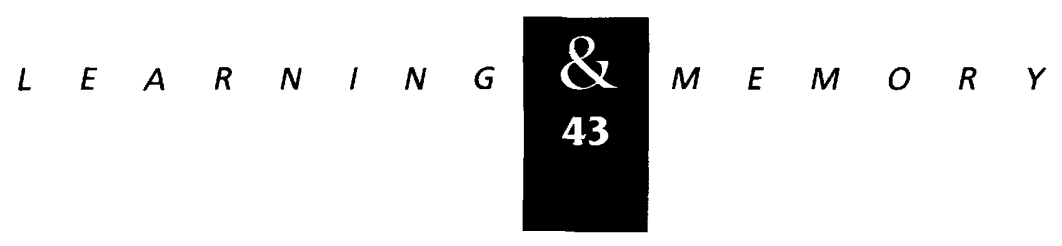




\section{Selig et al.}

\section{Results}

\section{NEW YORK GROUP EXPERIMENTS}

In this set of experiments, the perfusing medium initially contained DL-APV $(100 \mu \mathrm{M})$ and synaptic transmission was monitored until a stable baseline of 10 min was obtained $(<1 \%$ change in the EPSPs averaged over the first 5 min compared with the last $5 \mathrm{~min}, n=9$; Fig. 1 ). Following establishment of this baseline, $100 \mu \mathrm{M}$ 8-bromo-cGMP was applied to the preparation. As illustrated in Figure 1A, this produced no consistent effects on synaptic strength. After allowing $7.5 \mathrm{~min}$ for the drug to perfuse the tissue (control experiments established that 2-3 min is adequate for $10 \mu \mathrm{M}$ CNQX to completely block the field EPSPs; data not shown), a series of tetanic stimuli were delivered. Each tetanus consisted of 10 stimuli delivered at $100 \mathrm{~Hz}$ and nine such tetani were delivered separated by $30 \mathrm{sec}$. Synaptic strength was monitored beginning $30 \mathrm{sec}$ after the last tetanus and was minimally affected by the tetanic stimulation when measured 20 min after the end of the tetanic stimulation $(5 \pm 1 \%$ increase, average of EPSPS from 16-20 min after the tetani compared with the 5-min average preceding the tetani; Fig. 1A).

To test whether these same slices were capable of generating LTP, the 8-bromo-cGMP and DL-
APV were washed out for $20-30 \min (n=8$ of the nine experiments). After again ensuring that synaptic transmission was stable for at least $10 \mathrm{~min}$, the same series of tetani were delivered that now elicited stable LTP (Fig. 1B). Synaptic strength was increased by $80 \pm 1 \%$ when measured $15-20 \mathrm{~min}$ after the tetani and $51 \pm 3 \%$ when measured $45-50$ min after the tetani.

\section{BOSTON GROUP EXPERIMENTS}

In these experiments, the perfusing medium initially contained DL-APV $(50 \mu \mathrm{M})$ and synaptic strength was monitored until a stable 10- to 15min baseline was obtained. Following establishment of this baseline, $100 \mu \mathrm{M} 8$-bromo-cGMP was applied to the preparation for $5 \mathrm{~min}$ at which time a tetanus $(100 \mathrm{~Hz}, 1 \mathrm{sec})$ was applied to one of the two inputs. This caused a small increase in response ( $10 \pm 2 \%, n=5$; Fig. 2$)$ when measured 30 min after the tetanus. A small increase was also seen in the unstimulated pathways, and so this change is not considered significant. To test whether these same slices were capable of generating LTP, the 8-bromo-cGMP and DL-APV were washed out for $35 \mathrm{~min}$. After again ensuring that synaptic transmission was stable for $10-15 \mathrm{~min}$,

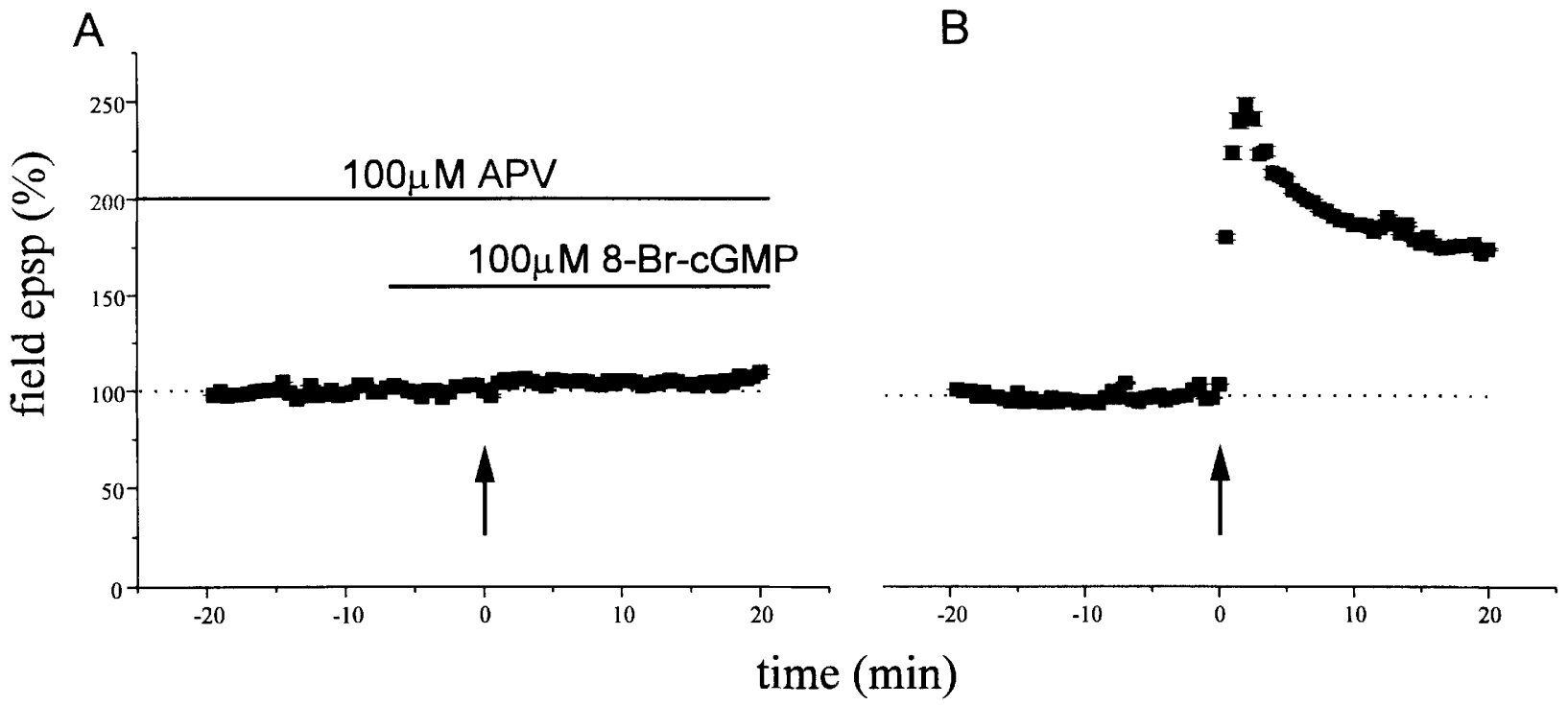

Figure 1: Results from the New York group indicate that the block of LTP by APV is not overcome by 8-bromo-cGMP. (A) Ensemble averages from nine experiments monitoring synaptic strength versus time. Slices initially bathed in $100 \mu \mathrm{M}$ DL-APV. After a stable baseline was established, $100 \mu \mathrm{M}$ 8-bromo-cGMP was added to the bath; $7.5 \mathrm{~min}$ later, a series of tetani were delivered (arrow; see text). $(B)$ In eight of the nine slices, cGMP and APV were washed out, a new baseline was established, and the same series of tetani were delivered (arrow). This generated robust LTP.

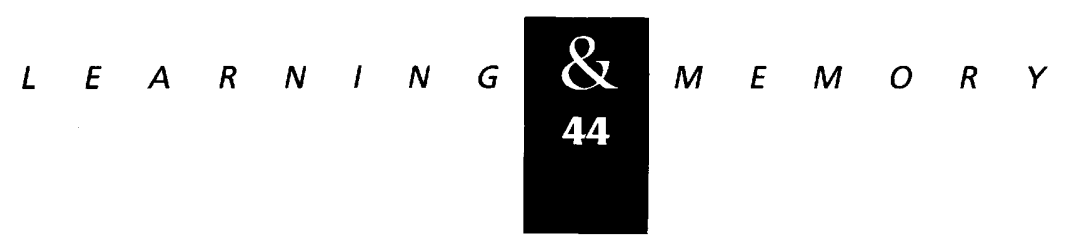



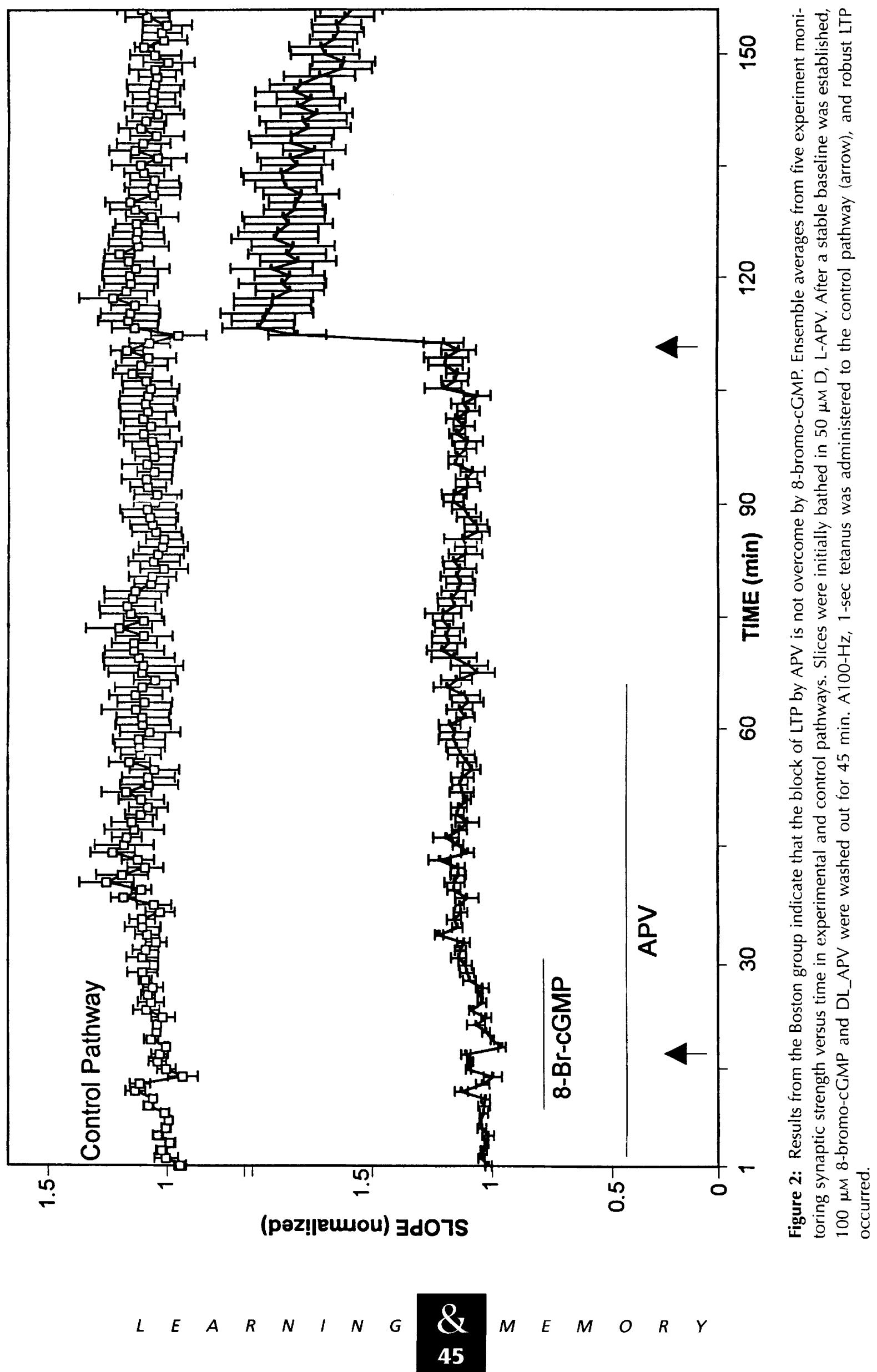


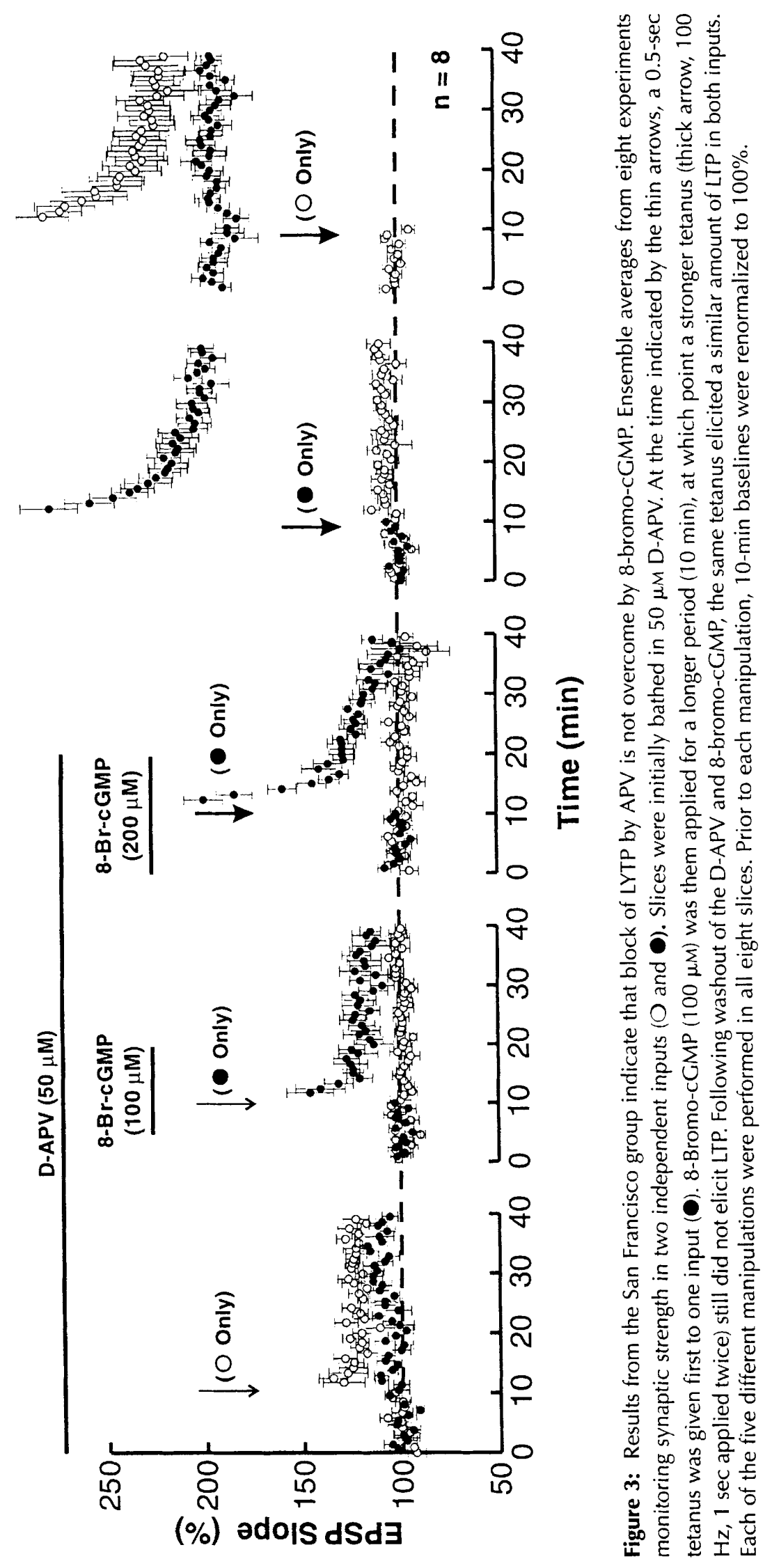

\begin{tabular}{llllllllllllllll}
\hline & $E$ & $A$ & $R$ & $N$ & $I$ & $N$ & $G$ & $\begin{array}{l}\boldsymbol{Q} \\
46\end{array}$ & $M$ & $E$ & $M$ & $O$ & $R$ & $Y$
\end{tabular} 
the tetanus was readministered and caused robust LTP ( $64 \pm 2 \%$ increase measured $30 \mathrm{~min}$ following the tetanus) (Fig. 2).

\section{SAN FRANCISCO GROUP EXPERIMENTS}

In this set of experiments, the experimental protocol was designed to mimic that of Zhuo et al. (1994) except that two independent inputs were used. These were alternately stimulated. Experiments were done on guinea pigs as in Zhuo et al. (1994). At the beginning of each experiment, D-APV $(50 \mu \mathrm{M})$ was applied and a 10 -min stable baseline was obtained. Because it has been reported that $50 \mu \mathrm{M}$ D-APV may not completely prevent NMDA receptor activation during tetanic stimulation in guinea pig (Hanse and Gustafsson 1995), the tetanus ( $50 \mathrm{~Hz}, 0.5 \mathrm{sec})$ was first applied to one input in the absence of 8-bromocGMP (Fig. 3). This caused a modest but significant enhancement of synaptic strength when measured $20-30 \mathrm{~min}$ after the tetanus $(24 \pm 4 \%$ increase, $n=8)$. 8-Bromo-cGMP ( $100 \mathrm{M})$ was then applied for $5 \mathrm{~min}$ at which point the same tetanus was applied to the other input resulting in an increase in synaptic strength that was not significantly different from that observed in the absence of 8-bromo-cGMP $(17 \pm 6 \%, P>0.3$, paired $t$-test; Fig. 3). To test whether the inability to generate LTP was attributable to inadequate levels of cGMP or insufficient activation of presynaptic terminals, a much stronger tetanus $(100 \mathrm{~Hz}, 1$ sec given twice separated by $20 \mathrm{sec}$ ) was subsequently given in the presence of a higher concentration of 8-bromo-cGMP ( $200 \mu \mathrm{M})$ applied $10 \mathrm{~min}$ before the tetanic stimulation. This pairing of strong tetanic stimulation with a high concentration of 8-bromo-cGMP still was insufficient to elicit LTP ( $10 \pm 7 \%$ increase). At the end of all of these experiments, the D-APV was washed out for 20-30 min and robust, stable LTP was generated (Fig. 3) by applying the strong tetanic stimulation first to the input that had just received this stimulation in the presence of D-APV ( $100 \pm 7 \%$ increase) and then to the other control input (124 $14 \%$ increase).

\section{Discussion}

In this study three independent laboratories have examined the role of CGMP in generating LTP by performing the critical experiment of pairing tetanic stimulation with bath application of 8-bromo-cGMP in the presence of APV. In contrast to previous reports (Zhuo et al. 1994; Arancio et al. 1995), this manipulation failed to generate LTP. These experiments were conducted in two different species (rat and guinea pig) using several different tetanic stimuli and the same or higher concentrations of 8-bromo-cGMP than had been used previously. The inability to generate LTP cannot be attributed to slice variability or poor health because all three groups found that the slices exhibited robust LTP following washout of the APV. The inability to generate LTP by pairing 8-bromocGMP with tetanic stimulation has also been reported by a fourth independent group (Schuman et al. 1994).

What could account for the differences between our findings and those of Zhuo et al. (1994)? Although we do not have a clear answer to this question, there are several possibilities. Subsequent to the publication of Zhuo et al. (1994), it was shown that tetanic stimulation in the presence of $50 \mu \mathrm{M} \mathrm{APV}$ can produce a small long-lasting synaptic enhancement (Hanse and Gustafsson 1995; Fig. 3) even without application of cGMP. This effect was not taken into consideration by Zhuo et al. (1994). A second possibility is that some potentiation may be explainable by the drift in baseline transmission evident in Figure 2d of Zhuo et al. (1994). A third possibility is that differences may stem from the fact that all of the present results were obtained using submerged slices, whereas Zhuo et al. (1994) used an interface recording chamber. A final possibility is that there are important differences in some unknown variable.

The experiments reported here do not provide any support for the proposal that an increase in presynaptic cGMP levels either alone or coupled with repetitive synaptic activation can produce potentiation or can overcome the block of LTP by APV. Thus, if retrograde messengers mediate the generation of LTP, some alternative intracellular cascade is presumably involved. Further work will be required to resolve this important issue.

\section{Acknowledgments}

This work was supported by grants from the National Institutes of Health (R.A.N., R.C.M., R.M., J.E.L.). D.K.S. was supported by a Howard Hughes Medical Institute

$$
\begin{array}{llllllllllllllll}
\hline & E & A & R & N & I & N & G & \begin{array}{l}
\boldsymbol{X} \\
47
\end{array} & M & E & M & O & R & Y
\end{array}
$$




\section{Selig et al.}

predoctoral fellowship. J.E.L. gratefully acknowledges the support of the W.M. Keck Foundation.

The publication costs of this article were defrayed in part by payment of page charges. This article must therefore be hereby marked "advertisement" in accordance with 18 USC section 1734 solely to indicate this fact.

\section{References}

Arancio, O., E.R. Kandel, and R.D. Hawkins. 1995. Activity-dependent long-term enhancement of transmitter release by presynaptic $3^{\prime}, 5^{\prime}$-cyclic GMP in cultured hippocampal neurons. Nature 376: 74-80.

Bear, M.F. and R.C. Malenka. 1994. Synaptic plasticity: LTP and LTD. Curr. Opin. Neurobiol. 4: 389-399.

Bliss, T.V.P. and G.L. Collingridge. 1993. A synaptic model of memory: Long-term potentiation in the hippocampus. Nature 361: 31-39.

Haley, J.E., P.L. Malen, and P.F. Chapman. 1993. Nitric oxide synthase inhibitors block long-term potentiation induced by weak but not strong tetanic stimulation at physiological brain temperatures in rat hippocampal slices. Neurosci. Lett. 160: 85-88.

Hanse, E. and B. Gustafsson. 1995. Long-term potentiation in the hippocampal CA1 region in the presence of $\mathrm{N}$-methyl-D-aspartate receptor agonists. Neurosci. 67: 531-539.

Huang, Y.Y., A. Colino, D.K. Selig, and R.C. Malenka. 1992. The influence of prior synaptic activity on the induction of long-term potentiation. Science 255: 730-733.

Irving, A.J., C.L. Boulton, J. Garthwaite, and G.L. Collingridge. 1993. cGMP may mediate transient synaptic depression in rat hippocampal slices. J. Physiol. 467: 182P.

Kullmann, D.M. and S.A. Siegelbaum. 1995. The site of expression of NMDA receptor-dependent LTP: New fuel for an old fire. Neuron 15: 997-1002.

Malinow, R., D.V. Madison, and R.W. Tsien. 1988. Persistent protein activity underlies long-term potentiation. Nature 335: 820-824.

Nicoll, R.A. and R.C. Malenka. 1995. Contrasting properties of two forms of long-term potentiation in the hippocampus. Nature 377: 115-118.

Schuman, E.M., M.K. Meffert, H. Schulman, and D.V. Madison. 1994. An ADP-ribosyltranferase as a potential target for nitric oxide action in hippocampal long-term potentiation. Proc. Natl. Acad. Sci. 91: 11958-11962.

Williams, J.H., M.L. Errington, Y.-G. Li, M.A. Lynch, and T.V.P. Bliss. 1993a. The search for retrograde messengers in long-term potentiation. Semin. Neurosci. 5: 149-158.

Williams, J.H., Y.-G. Li, A. Nayak, M.L. Errington, K.P.S.). Murphy, and T.V.P. Bliss. 1993b. The suppression of long-term potentiation in rat hippocampus by inhibitors of nitric oxide synthase is temperature and age dependent. Neuron 11: 877-884.

Zhuo, M., Y. Hu, C. Schultz, E.R. Kandel, and R.D. Hawkins. 1994. Role of guanylyl cyclase and cGMP-dependent protein kinase in long-term potentiation. Nature 368: 635-639.

Received January 10, 1996; accepted in revised form April 15, 1996. 


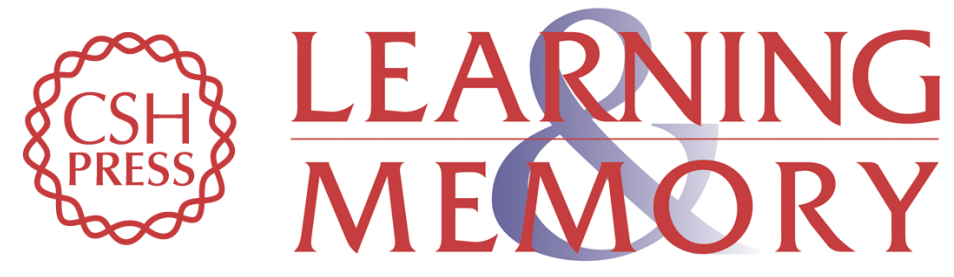

\section{Examination of the role of cGMP in long-term potentiation in the CA1 region of the hippocampus.}

D K Selig, M R Segal, D Liao, et al.

Learn. Mem. 1996, 3:

Access the most recent version at doi:10.1101/lm.3.1.42

References This article cites 14 articles, 2 of which can be accessed free at: http://learnmem.cshlp.org/content/3/1/42.full.html\#ref-list-1

License

Email Alerting Receive free email alerts when new articles cite this article - sign up in the box at the Service top right corner of the article or click here. 